\title{
Récepteurs hormonaux nucléaires et commutation des gènes de globine
}

Les gènes de globine humains de type $\beta$ sont organisés en batterie, dans l'ordre de leur expression au cours du développement: le gène $\varepsilon$ est exprimé dans le sac vitellin, les deux gènes ${ }^{\mathrm{A}} \gamma$ et ${ }^{\mathrm{G}} \gamma$ dans le foie foetal, enfin les gènes $\delta$ et $\beta$ sont activés à la fin de la gestation, lorsque la moelle osseuse devient le siège principal de l'érythropoïèse. L'activité de ces gènes est contrôlée par leurs régions régulatrices proximales et par un élément dominant, situé $10 \mathrm{~kb}$ en amont du gène $\varepsilon$ et nommé Locus Control Region ou LCR [1]. Les mécanismes responsables de cette commutation sont encore mal compris, mais ils semblent résulter de changements subtils dans l'expression de facteurs de transcription $\left(m / s\right.$ 1996, $n^{\circ} 4$, p. 533). Dans le cas des gènes $\gamma$, un certain nombre de séquences impliquées dans cette régulation ont été identifiées par l'étude de cas cliniques. La persistance héréditaire d'hémoglobine fotale (PHHF, ou HPFH en anglais) est une condition caractérisée par une synthèse soutenue de $\gamma$-globine à l'âge adulte. Les PHHF ont été associées, soit à des délétions dans le locus des gènes de $\beta$-globine, soit à des mutations ponctuelles dans l'un des promoteurs $\gamma$ $\left(m / s\right.$ 1994, $\left.n^{\circ} 3, p .346\right)$. Ces mutations peuvent être trouvées dans plusieurs régions, dont la région appelée «boîte CCAAT distale». Les mutations dans cette région modifient l'affinité de plusieurs facteurs de transcription, dont une protéine peu caractérisée, NF-E3 [2]. La régula- tion du gène de globine embryonnaire $\varepsilon$ a également été bien étudiée. Grâce à l'étude de souris transgéniques, les séquences responsables de l'extinction du gène $\varepsilon$ dans l'érythropoïèse définitive ont été localisées dans plusieurs régions en amont du gène, ainsi que dans le promoteur proximal. Dernièrement, on a constaté que la région de la boîte CCAAT distale des promoteurs des gènes embryonnaires $(\varepsilon$ et $\zeta$ ) et fœetaux $(\gamma)$ contient une répétition directe du type TGACCAATAGCCT [3]. Cette répétition n'apparaît pas dans les promoteurs des gènes exprimés à l'âge adulte, $\alpha$ et $\beta$. Elle ressemble aux sites de fixation de récepteurs hormonaux nucléaires non stéroïdiens qui sont constitués de répétitions directes du motif TGACCT. L'espacement des deux motifs (en abrégé, DR-n) contribue à la spécificité de reconnaissance des différents récepteurs (m/s 1994, $n^{\circ} 11$, p. 1171). Ainsi, l'élément présent dans les promoteurs $\varepsilon, \zeta$ et $\gamma$ peut être décrit comme un élément DR-1. Ces éléments peuvent a priori fixer les récepteurs de l'acide rétinoïque (dimères RXR-RAR ou RXRRXR), les peroxysome proliferator-activated receptors (RXR-PPAR), ainsi que divers récepteurs «orphelins» (dont le ligand, s'il existe, est inconnu) [4]. Dans les promoteurs des gènes de globines fœetaux et embryonnaires, le motif DR-1 est reconnu par le complexe NF-E3. Une mutagenèse spécifique a montré que la destruction des deux sites NF-E3 du promoteur $\varepsilon$ suf- fit à créer une persistance d'expression du gène $\varepsilon$ dans des souris transgéniques adultes. Dans des cellules érythroleucémiques, le complexe NFE3 contient un récepteur nucléaire orphelin, COUP-TF II, dont l'expression peut également être détectée dans la splanchnopleure intraembryonnaire, le sac vitellin et le foie foetal de souris. Dans ce dernier organe, l'expression de l'ARNm COUP-TF II atteint un apogée vers 12 jours de développement, c'est-àdire au moment de la commutation vers les globines adultes [3]. Ces résultats montrent l'importance de sites de fixation de récepteurs hormonaux nucléaires dans la commutation des globines, et indiquent que le récepteur orphelin COUP-TF II joue probablement un rôle important dans ce mécanisme [3].

V.M.

1. Elion J, Labie D. Mode d'action du LCR sur l'expression des gènes $\beta$-globine: les TAF entrent dans la danse. Med Sci 1996; 12: 397-9.

2. Ronchi AE, Bottardi S, Mazzucchelli C, Ottolenghi S, Santoro C. Differential binding of the NFE3 and CP1/NFY transcription factors to the human gamma- and epsilon-globin CCAAT boxes. J Biol Chem 1995; 270 : 21934-41.

3. Filipe A, Li Q, Deveaux S, et al. Regulation of embryonic/fetal globin genes by nuclear hormone receptors: a novel perspective on hemoglobin switching. EMBO J 1999; 18: 687-97.

4. Giguère V. Les récepteurs nucléaires orphelins: régulateurs essentiels du développement, de l'organogenèse et de l'homéostasie. Med Sci 1997; 13: 459-66.

SOCIÉTÉ DE BIOLOGIE 